\title{
Renal transplantation: its time we start!
}

There is a significant burden of chronic kidney disease (CKD) in Nepal and it is increasing everyday. There is global rise of Type 2 diabetes mellitus leading to CKD and other risk factors such as ageing population and systemic hypertension are also on rise. Because of lack of national registries and data maintenance in the general hospitals, exact burden of end-stage renal disease (ESRD) in Nepal is unknown.

Worldwide the number of patients receiving renal replacement therapy is estimated at more than 1.4 million $^{1}$, with incidence growing $8 \%$ annually $^{2}$. In developing countries like Nepal, the management of ESRD is largely guided by economic considerations. While renal transplantation (RT) remains the most rational treatment for patient with end-stage renal disease, the majority of the patient with ESRD receives dialytic therapy. Hemodialysis is mainly a short-term measure to support ESRD patients and bridge the gap to transplantation. Infection is a common complication in dialysis patients and many die of septicemia related complications rather than the disease itself. In Nepal, the majority of patients starting hemodialysis die or are forced to abandon treatment because of cost.

Since the first successful transplant of a kidney from one twin to another in 1954, RT has moved from being at the cutting edge to being a mature technology. Successful renal transplantation is associated with significant improvement in survival as well as quality of life. Compared to prolong dialysis it is more cost effective in patient requiring long term RT. Factors that should be considered before transplantation include the adequate supply of donor organs, the side effects of treatment, co-morbid disease in recipients, and equity of access to transplantation. Among the three renal replacement therapy options available, RT is the preferred mode, as it is most cost-effective and provides a better quality of life. The successful outcomes of RT over the last five decades have made RT as the optimum form of therapy for patients with CKD stage V. However, due to financial constraints and non-availability of organs, only about $5 \%$ of ESRD patients undergo transplant surgery.

In developing country like Nepal, due to limited access to renal replacement therapy, the ideal approach should be to reduce the incidence of ESRD and attempt preventive measures. Data on the cost-effectiveness of intervention in CKD is lacking, however it is recognized that CKD prevention would be most cost-effective as part of an integrated strategy targeting chronic vascular diseases. ${ }^{3}$ Multi drug regimens for the prevention of cardiovascular disease in at-risk populations have been shown to be cost effective. ${ }^{4} \mathrm{~A}$ study in a rural part of India has shown that with an integrated intervention to achieve acceptable blood pressure and diabetes targets to lower the prevalence of CKD was obtained at an annual cost of US\$ 0.43 per capita of population. ${ }^{5}$ This model can be applied in Nepal due to geographical and socio-economic similarity. However, when already diagnosed, they need proper treatment to increase the quality of life. Shrestha et al has concluded that optimization of therapy is needed in our patient to increase the quality of life of the patients with ESRD. ${ }^{6}$ Now when preemptive renal transplantation is in the process of getting recognition ${ }^{7}$, we are still far away from renal transplantation. Not only time has come, it is already late to re-start transplantation. A study has found that the economic and quality of life advantages of transplantation make it an attractive modality over dialysis, and coordinated efforts to facilitate safe and ethical transplantation in the countries with low income. ${ }^{8}$ Clear legal frameworks are lacking in Nepal regarding 
transplantation, leading to ambiguity on complex ethical issues and creating environments that facilitate commercial organ trafficking. A vast number of patients going abroad and candidates who can come up with the money for transplantation at home a waiting for the day when renal transplantation will start once again and continue forever.

\section{REFERENCES:}

1. Moeller S, Gioberge S, Brown g. ESRD patient in 2001: global overview of patients, treatment modalities and development trends. Nephrol dial transplant 2002; 17: 2071-6

2. Schieppati A, Remuzzi G. Chronic renal disease as a public health problem: epidemiology, social and clinical implications. Kidney Int Suppl 2005; 68 S98; 7-10

3. Gaziano TA, Opie LH, Weinstein MC. Cardiovascular disease prevention with a multidrug regimen in the developing world: a cost-effectiveness analysis. Lancet 2006;368:679-86.

4. Dirks JH, de Zeeuw D, Agarwal SK, Atkins RC, Correa-Rotter R, D'Amico G, et al. Prevention of chronic kidney and vascular disease: toward global health equity - the Bellagio 2004 Declaration. Kidney Int Suppl 2005;68 S98;1-6.

5. Mani MK. Nephrologists sans frontieres: Preventing chronic kidney disease on a shoestring. Kidney Int 2006;70:821-3

6. Shrestha S, Ghotekar LR, Sharma SK, Shangwa PM, Karki P. Assessment of Quality of Life in Patients of End Stage Renal Disease on Different Modalities of Treatment. J Nepal Med Assoc. 2008 Jan-Mar; 46 (169):1-6

7. Shrestha BM. Pre-emptive Renal Transplantation: Optimum Treatment for End-Stage Renal Disease? J Nepal Med Assoc. 2008 Jan-Mar;46(169):44-6

8. Global Alliance for Transplantation. Strategic direction setting and operational $\backslash$ guidelines. Montreal: The Transplantation Society; 2006. Available from: http://www. transplantation-soc.org/globalalliance.php 